\title{
Exercise Stress Testing in Healthy Subjects During Cholinergic Stimulation after a Single Dose of Pyridostigmine
}

\author{
Salvador M. Serra, Ricardo Vivacqua C. Costa, Bianca Gouvêa Bastos, Kelb Bousquet Santos, \\ Sérgio Henrique Rodolpho Ramalho, Antonio Claudio Lucas da Nóbrega \\ Niterói, RJ - Brazil
}

\begin{abstract}
Objective - The evaluation, by exercise stress testing, of the cardiorespiratory effects of pyridostigmine (PYR), a reversible acetylcholinesterase inhibitor.

Methods - A double-blind, randomized, cross-over, placebo-controlled comparison of hemodynamic and ventilation variables of 10 healthy subjects who underwent three exercise stress tests (the first for adaptation and determination of tolerance to exercise, the other two after administration of placebo or $45 \mathrm{mg}$ of $P Y R$ ).
\end{abstract}

Results - Heart rate at rest was: $68 \pm 3$ vs $68 \pm 3$ bpm before and after placebo, respectively $(P=0.38) ; 70 \pm 2 \mathrm{vs}$ $59 \pm 2 \mathrm{bpm}$, before and after pyridostigmine, respectively $(P<0.01)$. During exercise, relative to placebo: a significantly lower heart rate after $P Y R$ at, respectively, $20 \%$ $(P=0.02), 40 \%(P=0.03), 80 \%(P=0.05)$ and $100 \%$ $(P=0.02)$ of peak effort was observed. No significant differences were observed in arterial blood pressure, oxygen consumption at submaximal and maximal effort, exercise duration, respiratory ratio, $\mathrm{CO}_{2}$ production, ventilation threshold, minute ventilation, and oxygen pulse.

Conclusion - Pyridostigmine, at a dose of $45 \mathrm{mg}$, decreases heart rate at rest and during exercise, with minimal side effects and without interfering with exercise tolerance and ventilation variables.

Key words: autonomic nervous system, pyridostigmine, exercise stress testing.

Universidade Federal Fluminense, Niterói e Hospital Pró-Cardíaco, Rio de Janeiro Mailing address: Salvador M. Serra - Rua Paulino Fernandes, 25/802 - 22270-050 - Rio de Janeiro, RJ - Brazil
The autonomic nervous system interferes with the course of cardiovascular disease. The imbalance between sympathetic and parasympathetic activity on the heart influences the prognosis of heart disease, increasing the risk of events ${ }^{1}$.

Sympathetic activity reduction is associated with decreased cardiovascular morbidity and mortality ${ }^{2,3}$. Yet, although experimentally increased parasympathetic activity protects the ischemic myocardium from major cardiovascular events by raising the ventricular fibrillation threshold ${ }^{4-8}$, few studies aimed at autonomic equilibration via pharmacological parasympathetic stimulation are available ${ }^{9-13}$.

Recent work has shown that pyridostigmine (PYR), a reversible acetylcholinesterase inhibitor used in high oral doses for the treatment of myasthenia gravis, may become an alternative pharmacological treatment for obtaining autonomic system equilibration via efferent cholinergic stimulation of the heart ${ }^{14-16}$.

We conducted the initial clinical research on this drug to study the effects of a single dose of PYR on functional responses of the integrated cardiopulmonary system of healthy subjects during exercise, evaluating their responses to a programmed cardiovascular exercise protocol.

\section{Methods}

At first, a pilot study using a similar design as the present one, evaluated the effects of 30mg of PYR on healthy subjects undergoing cardiovascular exercise stress tests. At that dose, the drug reduced resting heart rate, but did not lead to other significant modifications or to adverse effects; these observations suggested that there was a safety margin for the present studies in which a higher dose (45mg) of PYR was used ${ }^{17}$.

Ten healthy volunteers were selected on the basis of the absence of history, signs, symptoms, or results of a physical examination suggestive of heart disease or any other acute or chronic disease. All subjects underwent a resting 12-lead electrocardiogram (ECG) and an initial 
echocardiography to identify functional or structural clinically undetected heart disease. Athletes, drug users, those with cardiac conduction or mitral valve prolapse, asthma, diabetes mellitus, conditions preventing exercise, and individuals showing intolerance to PYR or similar drugs were excluded from the study. The Ethics in Research Committee of the University Hospital Antonio Pedro, School of Medicine, UFF and the Ethics in Research Committee of the Pró-Cardíaco Hospital approved the study protocol. All volunteers signed a statement of informed consent once they understood the objectives and general details of the study. No funding from either pharmaceutical or equipment industries were received in the study.

Volunteers underwent three cardiopulmonary exercise test sessions according to a randomized, cross-over, double blind, placebo-controlled protocol. Increases in exercise intensity during the tests were not staggered and occurred in continuous increments according to the individualized ramp protocol.

The first test was intended to familiarize with the volunteers with the equipment and to identify the maximal aerobic capacity to exercise, planned to be reached after the ideal time period of $10 \mathrm{~min}$. The two subsequent tests should, for the same time intervals, have equal exercise intensities for each individual subject. Each volunteer was given placebo or $45 \mathrm{mg}$ of pyridostigmine bromide orally, in random fashion. The commercially available Mestinon tablets (Roche Laboratories, Brazil, batch 738392) was the source of the drug.

The same medical investigator made all three cardiopulmonary exercise tests at the same time of the day. Participants had a similar light meal, followed by a $2-\mathrm{h}$ period of fasting before the administration of drug or placebo.

Prior to the second and third stress tests, the following steps were applied in successive order: 1) a 15-min resting period in the supine position; 2) verification of arterial blood pressure at 5-min intervals in the right arm, for a total of three (averaged) values 3) 12-lead ECG, in the supine position; 4) record of heart rate of the ECG, after digital amplification, on lead $\mathrm{D}_{2} ; 5$ ) the administration of placebo or of a 45-mg PYR tablet; 6) 120min of clinical monitoring, in the absence of food intake; 7) successive repetition of items $1,2,3$ and $4 ; 8$ ) performance of the cardiopulmonary exercise stress test, applying the individualized ramp protocol.

During the cardiopulmonary exercise stress tests, expired gases were analyzed using the Teem 100 (AeroSport, USA); the treadmill, model 10200 (Inbramed, Brazil) with exercise intensity computer-directed increments, and the Elite 1.1 system of registration (Micromed, Brazil)

Every minute during exercise, the subjective feeling of tiredness was obtained from the volunteers, using Borg's scale from 0 to 10. Upon reaching this value, subjects were stimulated to carry on until their maximal limit, considered exhaustion.

Four ECG leads were monitored during the tests, with registration of the 13 leads, immediately prior to beginning, at every minute of effort, at peak effort and until the third minute in the recovery phase. The arterial blood pressure during these moments was also measured, sing a mercury column device (Oxigel, Brazil); to reduce the possibility of errors during the measurements, fractions of $2 \mathrm{mmHg}$ were considered.

Peripheral oxygen saturation was continuously measured during stress and until the $3^{\text {rd }}$ minute of recovery, by a 3700 digital Biiox oximeter (Ohmeda, USA).

Pulmonary ventilation (PV), oxygen consumption $\left(\mathrm{VO}_{2}\right)$, carbon dioxide production $\left(\mathrm{VCO}_{2}\right)$, oxygen $\left(\mathrm{PV} / \mathrm{VO}_{2}\right)$, and carbon dioxide $\left(\mathrm{PV} / . \mathrm{VCO}_{2}\right)$ ventilation equivalents, and oxygen pulse $\left(\mathrm{VO}_{2} / \mathrm{HR}\right.$ were recorded following every 20 s of effort, up to the $3^{\text {rd }}$ minute of the recovery phase. The spirometer used in all volunteers was of medium flow and had been previously validated by an international university institution ${ }^{8}$.

The beginning of the nonlinear ventilation was considered to identify ventilation thresholds. This point was identified by visual analysis of a minute volume vs. exercise time plot, evaluated by two experienced physicians, each of whom did not know each other's choices. Although other variables have been used for the study of the ventilation threshold, our method has been traditionally employed and was considered adequate.

The variables studied during the exercise tests were individually compared at equivalent exercise levels corresponding to respectively, 20, 40, 6080, and 100 percent of the maximal time of exercise performance. Data were tested to ascertain their normal distribution. They underwent two-way repeated measurements analysis of variance (ANOVA), in which main factors were the drug (placebo or pyridostigmine) and time (before and after treatment, at different exercise levels). Once significance was reached, post hoc analysis was made by Student's $t$ test for paired measurements, applying Bonferroni's correction. For proportion analysis the chi-square test was used, taking the number of collateral effects in the individuals into consideration. $\mathrm{P}<5 \%$ was considered the level of statistical significance.

\section{Results}

Seven of the 10 volunteers were female. Average age of the group was $28 \pm 2$ years; average weight, $67.4 \pm 52 \mathrm{~kg}$; height, $170 \pm 2 \mathrm{~cm}$. According to the randomization protocol, six volunteers used PYR prior to the first test, placebo prior to the second, and an inverse sequence in the other four.

There was a greater number of adverse effects following $45 \mathrm{mg}$ of $\mathrm{PYR}$ compared to placebo $(\mathrm{P}=0.041)$. No subject was excluded due to these adverse; on no occasion was drug treatment of these effects required. Following PYR, 4 volunteers had the following four symptoms, all of mild intensity: sialorrhea (three), abdominal pain and diarrhea (one of the three who had sialorrhea), and epigastric pain (one).

PYR did not interfere with the time of maximal exercise duration in the ramp protocol, which was as follows PYR: 
10.4 $\pm 0.5 \mathrm{~min}$; placebo: $10.8 \pm 0.6 \mathrm{~min} ;(\mathrm{P}=0.36)$. Similarly, $\mathrm{PYR}$ did not interfere with the absolute values of ventilation threshold (PYR: 24.3 $\pm 2.6 \mathrm{ml} / \mathrm{kg} / \mathrm{min}$; placebo: $25.7 \pm 2.7$; $(\mathrm{P}=0.19)$. Relative to percent maximal oxygen consumption, the ventilation threshold following PYR was $65.9 \pm 1.6 \%$, and after placebo, $66.0 \pm 1.9 \%(\mathrm{P}=0.48)$.

Compared with the postplacebo effect, following PYR, heart rate at rest was reduced (pre-PYR: $70 \pm 2 \mathrm{bpm}$, postPYR 59 \pm 2 bpm; ( $\mathrm{P}=0.004)$; preplacebo: $68 \pm 3 \mathrm{bpm}$; postplacebo: $68 \pm 3 ;(\mathrm{P}=0.38)$ (Figure 1), without interference in the PR interval: pre-PYR: $140.6 \pm 7.0 \mathrm{~ms}$; postPYR: $140.7 \pm 6.9 \mathrm{~ms} ;(\mathrm{P}=0.86)$.

During effort, a significant reduction in heart rate relative to placebo occurred at $20 \%(\mathrm{p}=0.02)$; at $40 \%(\mathrm{p}=0.03)$; at $80 \%(\mathrm{p}=0.05)$, and at $100 \%(\mathrm{p}=0.02)$ (Figure 2$)$.

PYR did not interfere with systolic blood pressure, (at rest - pre-PYR: $110 \pm 4 \mathrm{mmHg}$, postPYR: $106 \pm 4 \mathrm{mmHg}$; $\mathrm{P}=0.90$ ), or diastolic blood pressure (at rest - pre-PYR: 65 $\pm 2 \mathrm{mmHg}$, post-PYR: $65 \pm 2 \mathrm{mmHg}$; $\mathrm{p}=0.38$ ).

Statistics of the metabolic data of cardiopulmonary exercise stress tests did not show an effect of $45 \mathrm{mg}$ of pyridostigmine: respiratory maximal ratio-postPYR: $1.09 \pm 0.02$, postplacebo: $1.13 \pm 0.02(\mathrm{P}=0.40)$; oxygen pulse at maximal effort (in $\left.\mathrm{mlO}_{2} \cdot \mathrm{kg}^{-1} \cdot \mathrm{min}^{-1}\right) \cdot \mathrm{bpm}^{-1}$ - postPYR: $14.4 \pm 1.4$; postplacebo: $14.4 \pm 1.6(\mathrm{P}=0.93)$. Ventilation/minute at maximal effort postPYR: $68.1 \pm 6.6 / \mathrm{L} \cdot \mathrm{min}^{-1}$; postplacebo: 74.6 \pm 7,6L. $\mathrm{min}^{-1}$ $(\mathrm{P}=0.36)$; production of $\mathrm{CO}_{2}$ at maximal effort - postPYR: 2.85 $\pm 0.31 / \mathrm{L} \cdot \mathrm{min}^{-1}$; postplacebo: $3.25 \pm 0.31 \mathrm{~L} \cdot \mathrm{min}^{-1}(\mathrm{p}=0.22)$. No differences relative to oxygen consumption, in $\mathrm{mL} \cdot \mathrm{kg}^{-1} \cdot \mathrm{min}^{-1}$, measured at $20 \%$-postPYR: $12.9 \pm 1.3$, postplacebo:12.5 \pm 1.9 ; at $40 \%$ - postPYR: $19.0 \pm 2.8$, postplacebo: $19.4 \pm 3.1$; at $60 \%$ postPYR: $26.0 \pm 3.9$, postplacebo: $26.3 \pm 4.0$; at $80 \%$ - postPYR: $32.8 \pm 4.2$, postplacebo: $33.2 \pm 4.2$ and at $100 \%$ of maximal effortpostPYR: $37.4 \pm 4.0$, postplacebo: $38.9 \pm 4.3(\mathrm{P}=0.74)$ were observed (Figure 3 ).

\section{Discussion}

The most relevant observation of our study was the demonstration that pyridostigmine, at an oral dose of $45 \mathrm{mg}$, reduced heart rate not only at rest, but also during stress, when there is a progressive increase in sympathetic autonomic activity. Others ${ }^{14-16,19,20}$ using a dose of 30mg of PYR

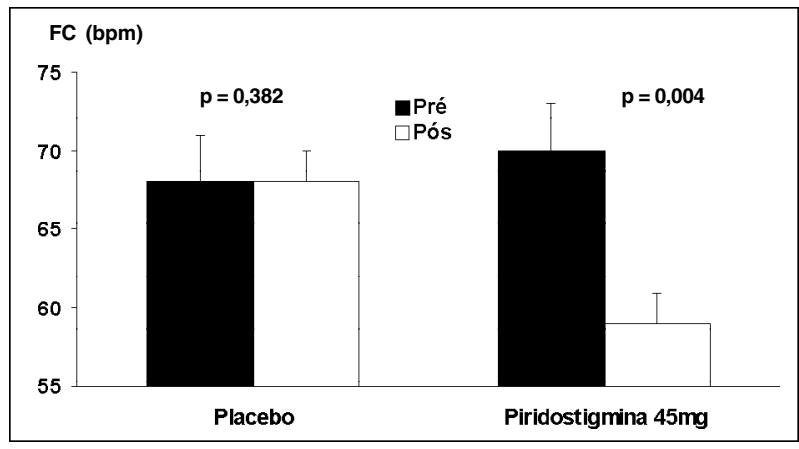

Fig. 1 - Heart rate during rest (before) and $2 \mathrm{~h}$ following (after) ingestion of placebo or pyridostigmine, $45 \mathrm{mg}$ orally $(\mathrm{n}=10)$.

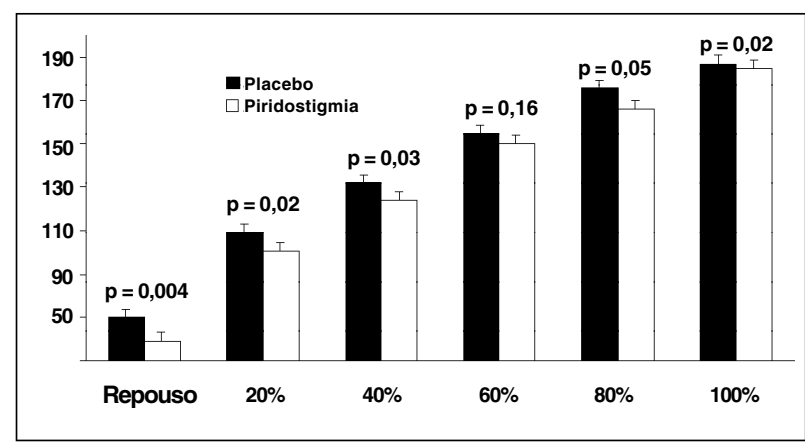

Fig. 2 - Heart rate at rest and during effort, postplacebo and postpyridostigmine, $45 \mathrm{mg} .20 \%, 40 \%, 60 \%, 80 \%, 100 \%=$ percent of maximal effort $(\mathrm{n}=10)$.

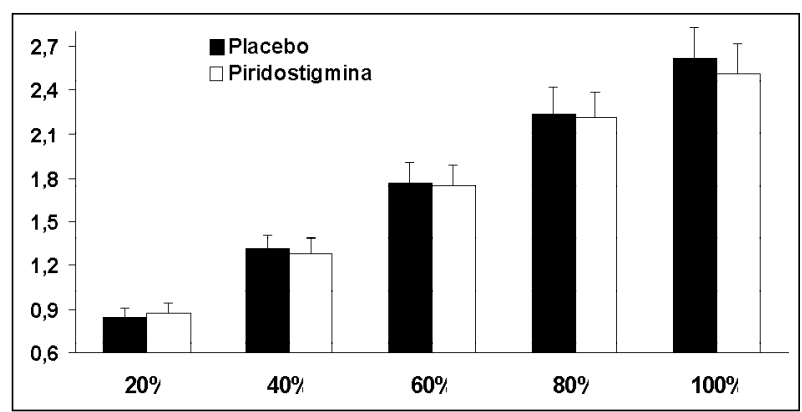

Fig. 3 - Oxygen consumption $\left(\mathrm{VO}_{2}\right)$ in $\mathrm{mL} / \mathrm{kg} / \mathrm{min}$, during postplacebo and postpyridostigmine, $45 \mathrm{mg}$, efforts. $20 \%, 40 \%, 60 \%, 80 \%, 100 \%=$ percent of maximal effort, $\mathrm{P}=0.74(\mathrm{n}=10)$.

had already observed the reduction in heart rate at rest shown in this study.

Few studies of the effects of PYR during exercise are available. Arad et al. ${ }^{21}$, studied eight hypertensive individuals on beta-blocker treatment, who underwent exercise stress on the ergometer, without analysis of expired gases, following the ingestion of $30 \mathrm{mg}$ of PYR. No reduction in heart rate was observed. Stephenson and Kolka ${ }^{19}$, on the other hand, following the administration of $30 \mathrm{mg}$ of PYR, observed an average reduction in heart rate of 9 beats per min in five individuals who had previously undergone a 30 min period of ergometer exercise, at an intensity of $55 \%$ of peak $\mathrm{VO}_{2}$. Heart rate was measured at the $25^{\text {th }}$ minute of exercise. Our observation of an average reduction in heart rate of $8 \mathrm{bpm}$ at $40 \%$ of peak effort, using $45 \mathrm{mg}$ of PYR parallels the results of Stephenson and Kolka ${ }^{19}$. The divergence between our results on heart rate, and those of Arad et al. ${ }^{21}$ may be attributed to the concomitant use of a cardiodepressor agent by these authors.

A $15 \%$ to $40 \%$ reduction in serum cholinesterase activity was obtained in previous studies using $30 \mathrm{mg}$ of PYR ${ }^{15,22}$. The presently observed reduction of heart rate following PYR administration indicates that the volunteers were indeed under acetylcholinesterase blockade.

Because of the bradycardiac effect of PYR at rest and during effort, evidenced in the present study, one can expect that PRY may have a beneficial effect on the decrease heart rate per se. According to Levine ${ }^{23}$, all mammals have an in- 
verse semilogarithmic relationship between heart rate and life expectancy. A study on a universal biological scale of mortality suggests that basal energy consumption per body atom per heart beat is the same in all animals: approximately $10^{-8}$ molecules per beat, suggesting that life expectancy is predetermined by the energetic bases of the living cell, and that heart rate reflects an epiphenomenon in which heart rate itself is the marker of metabolic expenditure. Levine ${ }^{23}$ recommends that research should be done to confirm that human life can be really extended by reducing heart rate, and that clinical studies to evaluate the therapeutic effect of bradycardia should be performed.

Several studies ${ }^{24}$ have shown that subjects with lower heart rates tend to have lower mortality rates consequent to stroke, cancer, coronary artery disease as well as a lower global mortality rate. Recent research involving 4,756 subjects of both sexes between 40 and 80 years of age also concluded that heart rate is a predictor of mortality, independently of other associated risk factors ${ }^{25}$. Without discarding possible benefits inherent to a reduction of heart rate in young healthy individuals, it should be emphasized that our volunteers differ from some populations reported in these studies.

Our work did not demonstrate an effect of pyridostigmine on systolic and diastolic blood pressure levels at rest or during exercise. Although we did not expect an alteration because only healthy individuals took part in this research, the normal pressure response during exercise under enhanced cholinergic stimulation, indirectly suggests that ventricular function took place without limitations. The normal kinetics of the oxygen pulse in volunteers during effort supports this observation. On the other hand, different than Arad et al. ${ }^{21}$, in our study diastolic blood pressure during rest or stress showed no difference following PYR administration when compared to placebo. The concomitant use of a beta-blocker by patients in the study by Arad et al. ${ }^{21}$ may have induced a more effective opposition to the vasoconstrictor action of the beta-blocker, reducing vascular peripheral resistance during stress and determining a fall in diastolic blood pressure.

Regarding the cardiopulmonary stress test, a procedure known to be of high reproducibility in the evaluation of metabolic parameters during exercise ${ }^{26}$, pyridostigmine did not cause significant changes in $\mathrm{CO}_{2}$ production and exhaled minute volume. These data acquire greater significance because cholinesterase inhibitors like PYR effect the bronchial tree favoring smooth muscle contraction. This has induced in caution in its prescription to asthmatic patients and is the reason for their exclusion from our study.

Because PYR led to reduced heart rate without modifying oxygen consumption during stress, we expected to observe an increase in oxygen pulse compared to placebo. However, because oxygen pulse is also influenced by the arteriovenous difference in $\mathrm{O}_{2}$ content, it is possible that a decreased cardiac output during exercise occurred, so that $\mathrm{VO}_{2}$ was maintained at the expense of an increase in the arteriovenous oxygen difference. Another explanation could be the scatter of $\mathrm{VO}_{2}$ and heart rate data.
PYR did not interfere in the duration in minutes of the test or in the submaximal and maximal $\mathrm{VO}_{2}$, or the ventilation threshold. These data indicate the favorable metabolic effect of PYR and contrasts with the results of previous work evaluating healthy individuals-using beta-blockers. Some of these studies showed reduced submaximal oxygen consumption $^{27}$, and a decrease of 40 to $60 \mathrm{~s}$ in exercise duration ${ }^{28}$. Thus, the reduced heart rate caused by PYR, by not involving conditions that may lead to fatigue during submaximal exercise may be interpreted as favorable by avoiding the need to limit subjects' daily activities.

Autonomic nervous system dysfunction is associated with an unfavorable prognosis in various cardiovascular diseases. Autonomic in balance may precipitate sudden death and a worsening of chronic coronary artery disease, of acute myocardial infarction ${ }^{29,30}$, hypertrophic cardiomyopathy ${ }^{31,32}$, cardiac failure ${ }^{33,34}$, dilated cardiomyopathy ${ }^{35}$, syndrome $\mathrm{X}^{36}$, hypertension ${ }^{37}$, insulin resistance ${ }^{38}$, and diabetes mellitus ${ }^{38}$.

Pharmacological reduction in sympathetic activity with beta-blockers in ischemic heart disease decreases cardiovascular mortality by approximately $23 \%$ 2,3,39. This and other favorable results have led to the generalization of the prescription of this group of drugs and the later discovery of beta-blockers with other associated effects ${ }^{40}$. However, the specific reduction of parasympathetic activity in acute myocardial infarct survivors is an indication for a poor prognosis ${ }^{41}$. Several studies associate decreased vagal activity with an increase in cardiovascular mortality ${ }^{42-47}$. Successful coronary thrombolysis performed up to $12 \mathrm{~h}$ after an acute myocardial infarct is associated with increased heart rate variability, indicating greater vagal activity ${ }^{48}$. Functional autonomic preservation of the heart following restoration of coronary patency is one of the factors determining a better prognosis ${ }^{48}$.

Thus, there is a confluence of opinions attributing a worse prognosis, not only to the increase in sympathetic activity but also to reduced parasympathetic activity, which appears to effectively contribute to such unfavorable prognoses.

Few studies, however, were designed to show the pharmacological effects of increased parasympathetic activity. In 1993, four independent groups ${ }^{9-12}$ published articles evaluating the effects of scopolamine and agents that at low doses act as cholinomimetics. They showed a reduction in heart rate and an increase in its variability. Hull et al. ${ }^{49}$ in 1995 failed to identify modifications of ventricular fibrillation threshold following the use of scopolamine. This result did not confirm studies showing a protective antifibrillatory effect following experimental parasympathetic stimulation. The paradoxical effect of scopolamine, which at high doses becomes a cholinergic blocker, limits the usefulness of studies using higher doses of this drug.

Recently, the ATRAMI study designed to investigate vagal reflexes in 1284 patients within less than 28 days follo- 
wing an acute myocardial infarction showed the prognostic value of vagal activity, independently of ventricular function or the presence of cardiac arrhythmia ${ }^{50}$. In their conclusion, the authors emphasized the need for research enabling the therapeutic correction of autonomic in balance, thus contributing to the reduction of cardiac mortality.

Being a reversible inhibitor of acetylcholinesterase and thus resulting in greater availability of acetylcholine at effector organs, pyridostigmine has been studied for its a dose-dependent effect, for being active following oral administration, for having been used for decades at high doses for the treatment of myasthenia gravis, and by being associated with a low incidence of collateral effects.

Recent studies evaluating the effects of pyridostigmine on the cardiovascular system of healthy subjects have shown: 1) absence of hemodynamic or functional ventricular damage on echocardiography ${ }^{16} ; 2$ ) increased heart rate variability for over $24 \mathrm{~h}^{17} ; 3$ ) attenuation of the double pro- duct increased after mental stress ${ }^{51}$; and 4) reduced QTc dispersion in the resting $\mathrm{ECG}^{18}$. In addition, an experimental study with anesthetized rats during central nervous stimulation showed reduced myocardial oxygen consumption following PYR administration ${ }^{52}$. This research, some of it still in its initial stages, signals the convenience of possible clinical applications. The favorable evidence of the present study adds to that reported elsewhere.

In conclusion, the cholinergic effect of pyridostigmine at the dose of $45 \mathrm{mg}$ in healthy subjects led to reduced resting and exercise heart rates, did not interfere with ventilation variables or tolerance to exercise, having minimal untoward effects. These results suggest the need for further studies aimed at the evaluation of pyridostigmine's effects in cardiovascular patients, with the perspective of pharmacological modification of the autonomic nervous system possibly favorably affecting the prognosis of such conditions.

\section{References}

1. Barron HV, Michael DL. Autonomic nervous system and cardiac death. J Am Coll Cardiol 1996; 27: 1053-60.

2. Frishman HW, Furberg CD, Friedwald W, et al. Beta-adrenergic blockade for survivors of acute myocardial infarction. N Engl J Med 1984; 312: 830-7.

3. ISIS I (First International Study on Infarct Survivel) Collaborative Group. Randomized trial of intravenous atenolol among 16027 cases of suspect acute myocardial infarction. Lancet 1986; 2: 57-66.

4. Marsh JD, Smith TW. Agonist binding to hight affinity beta adrenergic receptors in culture heart cells. Clin Res 1983; 31: 46 ${ }^{\mathrm{A}}$.

5. Ferrara R, Bonaduce $\mathrm{D}$, Abete $\mathrm{P}$, et al. Role of cholinergic activity in reperfusion induced ventricular arrytmias. Cardiovasc Res 1998; 21: 279-85.

6. Billmann GE, Schwartz PJ, Stone HL. The effects of daily exercise on susceptibility to sudden death. Circulation 1984; 69: 1182-9.

7. Billmann GE. Effects of cholinergic agonist carbachol and cyclic guanosine monophosphate on sudden death. J Am Coll Cardiol 1989; 91: 13

8. De Ferrari GM, Salvati P, Ukmar G, et al. Manipulation of the autonomic nervous system in the prevention of the sudden death. Circulation 1990; 82: 637.

9. Casadei B, Pipilis A, Sessa F, Conway J, Sleight P. Low doses of scopolamine increase cardiac vagal tone in the acute phase of myocardial infarction. Circulation 1993; 88: 353-7.

10. De Ferrari GM, Mantica M, Vanoli E, et al. Scopolamine increases vagal tone and vagal reflexes in patients after myocardial infarction. J Am Coll Cardiol 1993; 22: 1327-34.

11. Pedretti R, Colombo E, Simona SB, et al. Influence of transdermal scopolamine on cardiac sympathovagal interaction after acute myocardial infarction. Am J Cardiol 1993; 72: 384-92.

12. Vybiral T, Glaeser DH, Morris G, et al. Effects of low dose transdermal scopolamine on heart rate in normal acute myocardial infarction. J Am Coll Cardiol 1993; 22: 1320-6.

13. Kochiadakis GE, Rombola AT, Kanoupakis EM, et al. Effect of transdermal scopolamine on heart rate variability in patients with severe coronary heart disease. Pacing Clin Eletrophysiol 1996; 19: 1869-71.

14. Pontes P, Bastos BG, Mesquita E, Nóbrega ACL. Efeitos da estimulação colinérgica com piridostigmina em voluntários saudáveis: análise ecodopplercardiográfica e hemodinâmica. Arq Bras Cardiol 1999; 72: 297-306.

15. Reis AF, Bastos BG, Mesquita LJ, Romeo $F^{\circ}$ LJ, Nóbrega ACL. Disfunção parassimpática, variabilidade da frequiência cardíaca e estimulação colinérgica após infarto agudo do miocárdio. Arq Bras Cardiol 1998; 70: 193-9.

16. Castro RRT, Serra SM, Nóbrega ACL. Redução da dispersão do intervalo QTc: potencial mecanismo de proteção cardíaca do brometo de piridostigmina. Arq Bras Cardiol 2000; 75: 205-9.
17. Serra SM, Vivacqua R, Ramalho SHR, Santos KB, Bastos BG, Nóbrega ACL. Cardiopulmonary exercise testing during cholinergic stimulation with pyridostigmine in healthy subjects. J Am Coll Cardiol 1998; 31: 407C.

18. Wideman L, Stoudemire NM, Pass KA, McGinnes CL, Gaesser GA, Weltman A. Assessment of the Aerosport TEEM 100 portable metabolic measurement system. Med Sci Sports Exerc 1996; 28: 509-15.

19. Stephenson LA, Kolka MA. Acethylcolinesterase inhibitor, pyridostigmine bromide reduces skin blood flow in humans. Am J Physiol 1990; 258: R951-R7.

20. Nóbrega ACL, Carvalho ACG, Bastos BG. Resting and reflex heart rate responses during cholinergic stimulation with pyridostigmine in humans. Braz J Med Biol Res 1996; 29: 1461-5.

21. Arad M, Roth A, Zelinger J, et al. Safety of pyridostigmine in hypertensive patients receiving beta blockers. Am J Cardiol 1992; 69: 518-22.

22. Epstein Y, Arnon R, Moran D, et al. Effect of pyridostigmine on the exercise-heat response of man. Eur J Appl Physiol 1990; 61: 128-32.

23. Levine HJ. Rest heart rate and live expectancy. J Am Coll Cardiol 1997; 30: 1104-6.

24. Wilhelmsen L, Berglund G, Elmeeldi D, et al. The multifactor primary prevention trial in Göteborg. Sweden. Eur Heart J 1986; 7: 279-88.

25. Mensink GBM, Hoffmeister H. The relationship between resting heart rate allcause, cardiovascular and cancer mortality. Eur Heart J 1997; 18: 1404-10.

26. Serra S. Considerações sobre Ergoespirometria. Arq Bras Cardiol 1997; 68: 301-4.

27. Twentyman OP, Disley A, Gribbin HR, Alberti KG, Tattersffield AE. Effect of betaadrenergic blockade on respiratory and metabolic responses to exercise. J Appl Physiol 1981; 51: 788-93.

28. Hughson RL. Ramp work tests with three different beta-blockers in normal human subjects. Eur J Appl Physiol 1989; 58: 710-6.

29. Schwartz PJ, Motolese M, Pollavinini G, et al. The sudden death italian prevention group. Prevention of sudden death after a first myocardial infarction by pharmacological or surgical antiadrenergic interventions. J Cardiovasc Eletrophysiol 1988; 3: 2-16.

30. Vanoli E, Schwartz PJ. Sympathetic-parasympathetic interaction and sudden death. Basic Res Cardiol 1990; 85: 305-21.

31. Bonaduce $\mathrm{D}$, Petretta $\mathrm{M}$, Betocchu $\mathrm{S}$, et al. Heart rate variability in patients with hypertrophic cardiomyopathy: association with clinical and echocardiographic features. Am Heart J 1997; 134: 165-72.

32. Limbruno U, Strata G, Zucchi R, et al. Altered autonomic cardiac control in hypertrophic cardiomyopahy. Role of out flow tract obstruction and myocardial hypertrophy. Eur Heart J 1998; 19: 146-53.

33. Kaye DM, Lefkovits J, Jennings GL, Bergin P, Broughton A, Esler MD. Adver- 
se consequences of high sympathetic nervous activity in the failing human heart. J Am Coll Cardiol 1995; 26: 1257-63.

34. Ponikowski P, Chua TP, Piepoli M, et al. Ventilatory response to exercise correlates with impaired heart rate variability in patients with chronic congestive heart failure. Am J Cardiol 1998; 82: 338-44.

35. Hoffmann J, Grim W, Knop U, Maisch B. Heart rate variability and major arrhythmic events in patients with idiophatic dilated cardiomyopathy. Pacing Clin Electrophysiol 1996; 19: 1841-4

36. Ponikowski P, Rosano GM, Amadi A, et al. Transient autonomic dysfunction precedes ST-segment depression in patients with syndrome X. Am J Cardiol 1996; 77: 942-7.

37. Jullius S, Nesbitt SD. Clinical consequences of the autonomic imbalance in hypertension and congestive heart failure. Scan Cardiovasc J 1998; 47: 23-30.

38. Jullius S, Palatini P, Nesbitt SD. Tachycardia: na important determinant of coronary risk in hypertension. J Hypertens 1998; 16: S9-S15.

39. Bigger JT, Coromilas ASJ. How do beta-blockers protect after myocardial infarction? Am Int Med 1984; 101: 256-8.

40. Packer M, Bristow MR, Cohn JN, et al. The effect of carvedilol on morbidity and mortality in patients with chronic heart failure. N Engl J Med 1996; 334 1349-55.

41. Kleiger RE, Miller JP, Bigger JT. Heart rate variability: a variable predicting mortality following acute myocardial infarction. J Am Coll Cardiol 1984; 3 : 547-50.

42. La Rovere MT, Specchia G, Mortara A, Schwartz PJ. Baroreflex sensitivity, clinical correlates, and cardiovascular mortality among patients with a first myocardial infarction: a prospective study. Circulation 1988; 78: 816-24.

43. Hull SS, Evans AR, Vanoli E. Heart rate variability before and after myocardial infarction in conscious dogs at high and low risk of sudden death. J Am Coll Cardiol 1990; 16: 978-85.
44. Cripps TR, Malik M, Farrel TG, Cann AJ. Prognostic value of reduced heart rate variability after myocardial infarction: clinical evaluation of a new analysis method. Br Heart J 1991; 65: 14-9.

45. Farrel TJ, Bashir Y, Cripps TR, et al. Risk stratification for arrytmics events in post infarction patients based on heart rate variability, ambulatory electrocardiographic variables and the signal-average electrocardiogram. J Am Coll Cardiol 1991; 18: 687-97

46. Bigger JT Jr, Fleiss JL, Steinmman RC, Rolnitzky LM, Kleiger RE, Rottman JN. Correlations among time and frequency domain measures of heart period variability two weeks after acute myocardial infarction. Am J Cardiol 1992; 69: 891-8.

47. Casolo GC, Stroder P, Signorini C. Heart rate variability during the acute phase of myocardial infarction. Circulation 1992; 85: 2073-9.

48. Kelly PA, Nolan J, Wilson JI, Perrins EJ. Preservation of autonomic function following successful reperfusion with streptokinase within 12 hours of the onset of acute myocardial infarction. Am J Cardiol 1997; 79: 203-5.

49. Hull SH, Vanoli E, Adamson PB, et al. Do increases in markers of vagal activity imply protection from sudden death? The case scopolamine. Circulation 1995; 91: 2516-9.

50. La Rovere MT, Bigger JT, Marcus FI, Mortara A, Schwartz, for the ATRAMI (Autonomic Tone and Reflexes after Myocardial Infarction) Investigators. Baroreflex sensitivity and heart rate variability in prediction of total cardiac mortality after myocardial infarction. Lancet 1998; 351: 478-84.

51. Nóbrega ACL, Carvalho ACG, Santos KB, Soares PPS. Cholinergic stimulation with pyridostigmine blunts the cardiac responses to mental stress. Clin Auton Res 1999; 9: 1-6.

52. Grabe-Guimarães A, Alves LM, Tibiriçá E, Nóbrega ACL. Pyridostigmine blunts the increase in myocardial oxygen demand elicited by stimulation of the central nervous system in anesthetized rats. Clin Auton Res 1999; 9: 83-9.

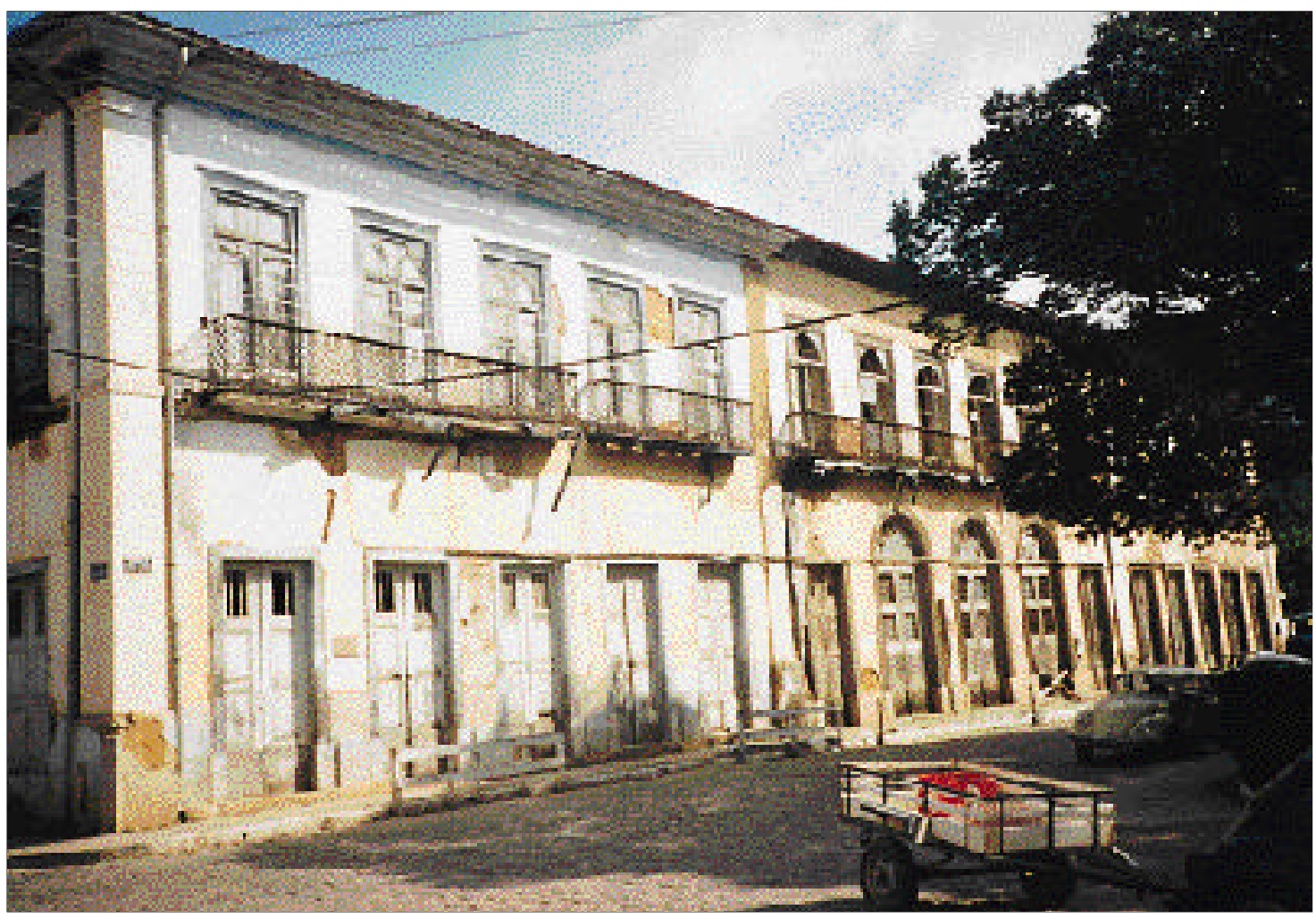

Bananal - Vale do Paraíba, SP

Flavia Cardoso

Editor da Seção de Fotografias Artísticas: Cícero Piva de Albuquerque Correspondência: InCor - Av. Dr. Enéas C. Aguiar, 44 - 05403-000 - São Paulo, SP - E-mail: delcicero@incor. usp.br 